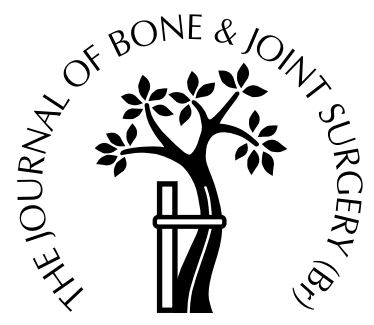

\title{
The hyperabduction test
}

\section{AN ASSESSMENT OF THE LAXITY OF THE INFERIOR GLENOHUMERAL LIGAMENT}

\author{
O. J. Gagey, N. Gagey \\ From Bicêtre Hospital, Paris-South University and the Institute of Anatomy, Paris, \\ France
}

W e studied 100 fresh human shoulders in cadavers (mean age 76 years), and the range of passive abduction (RPA) in 100 volunteers with normal shoulders and in 90 patients with instability of the joint, over a period of six years.

The anatomical and clinical findings showed that passive abduction occurs within the glenohumeral joint only, is controlled by the inferior glenohumeral ligament and has a constant value in $95 \%$ of both shoulders in normal subjects. In patients with instability, $85 \%$ showed an RPA of over $105^{\circ}$ with $90^{\circ}$ in the contralateral shoulder. In the remaining patients a strongly positive apprehension test suggested a diagnosis of instability.

An RPA of more than $105^{\circ}$ is associated with lengthening and laxity of the inferior glenohumeral ligament.

J Bone Joint Surg [Br] 2000;82-B:69-74.

Received 5 October 1999; Accepted after revision 3 May 2000

The sulcus and drawer tests ${ }^{1,2}$ for the assessment of laxity of the shoulder are performed in positions of the joint in which the ligaments are relaxed. They examine a complex situation and not the laxity of a particular ligament. Laxity of the inferior glenohumeral ligament (IGHL) is an essential factor contributing to both atraumatic and multidirectional instability of the shoulder. ${ }^{2,3}$ Some authors ${ }^{4}$ believe that it may also be present in patients with instability after injury. Clinical methods of assessing such laxity have not been described previously.

We have tested the role of the IGHL in the restriction of movement of the glenohumeral joint $(\mathrm{GHJ})$, and investigated the possibility of a clinical assessment of its laxity.

O. J. Gagey, MD, PhD, Professor

Orthopaedic Department, Bicêtre Hospital, Paris-South University and Institute of Anatomy, 45 rue des Saints Pères, 75006 Paris, France.

N. Gagey, MD, PhD, Radiologist

38 rue de Verdun, 59000 Nancy, France.

Correspondence should be sent to Professor O. J. Gagey at 78 Avenue du Général Leclerc, 94270 le Kremlin-Bicêtre, France.

(C)2000 British Editorial Society of Bone and Joint Surgery 0301-620X/00/110628\$2.00

\section{Patients and Methods}

There were three parts to the study: 1) in cadavers; 2) in volunteers; and 3) in patients with instability of the shoulder after injury.

Study in cadavers. We obtained 100 fresh normal human shoulders, 68 from women and 32 from men, with a mean age of 76 years (61 to 82). The scapula was fixed on a rigid frame with its medial edge vertical and the blade lying at an angle of $30^{\circ}$ anterior to the coronal plane to reproduce the normal position along the thorax. All the muscles of the GHJ were removed leaving the ligaments intact and the joint cavity closed.

The maximum range of movement in all planes was measured using a goniometer. The landmark used to check the position of the arm was a line from the posterior edge of the acromion to the lateral epicondyle. The structures responsible for limitation of movement were observed. Measurements were made in neutral rotation. The ranges of abduction and elevation were recorded before and after section of the IGHL.

Study in volunteers. There were 100 volunteers, 63 men and 37 women with a mean age of 28 years (24 to 38).

Clinical. In order to measure the range of passive abduction (RPA), the physician stood behind the patient with his

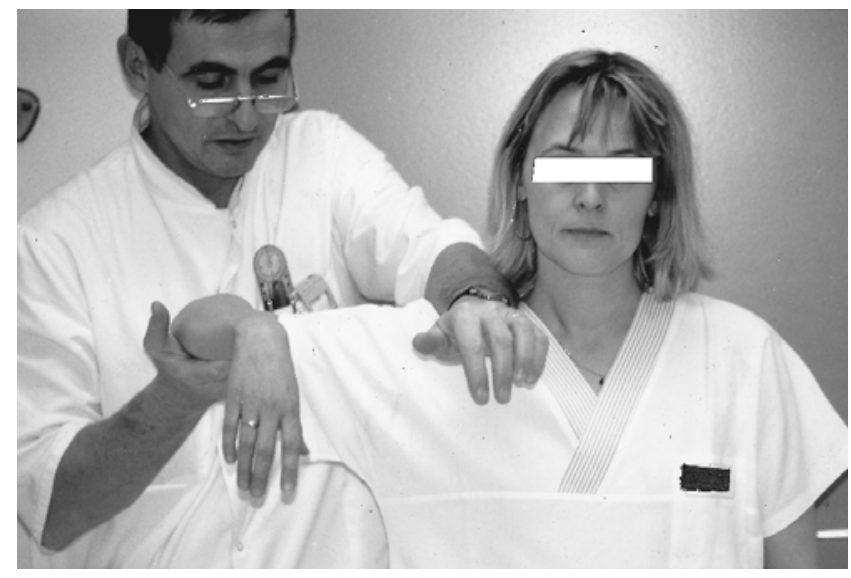

Fig. 1

Photograph showing the technique of the test. The forearm of the physician holds the shoulder girdle firmly in the lower position and the other hand lifts the patient's arm up in the frontal plane. In this case the hyperabduction test is negative. 

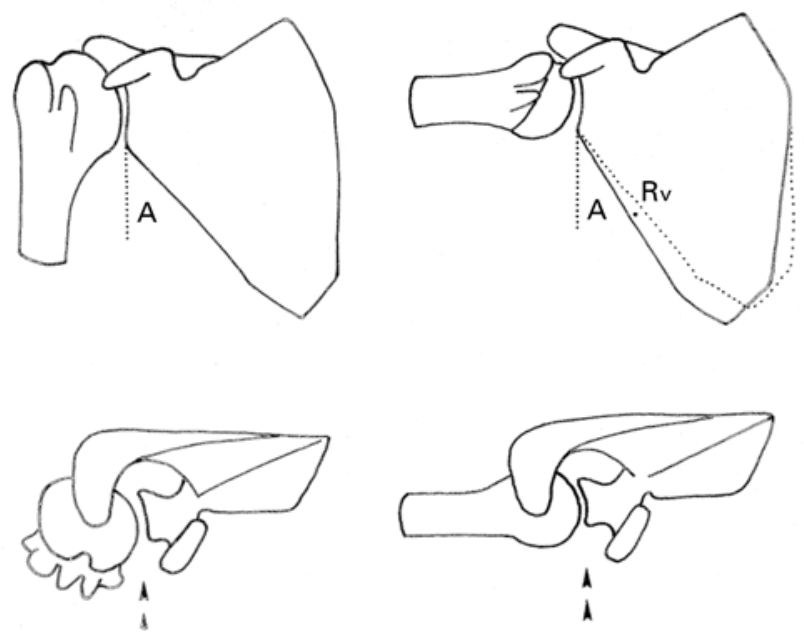

Fig. 2

Diagrams of the radiographs taken. The arrowheads indicate the direction of the beam. A is the angle between the axillary border of the scapula and the vertical. $\mathrm{Rv}$ is obtained by subtracting the value of A measured at rest from that in passive abduction. Left, initial position of scapula; right, full passive abduction. The scapula rotates up to $5^{\circ}$ during the test so that the measured range of passive abduction corresponds to the abduction within the GHJ.

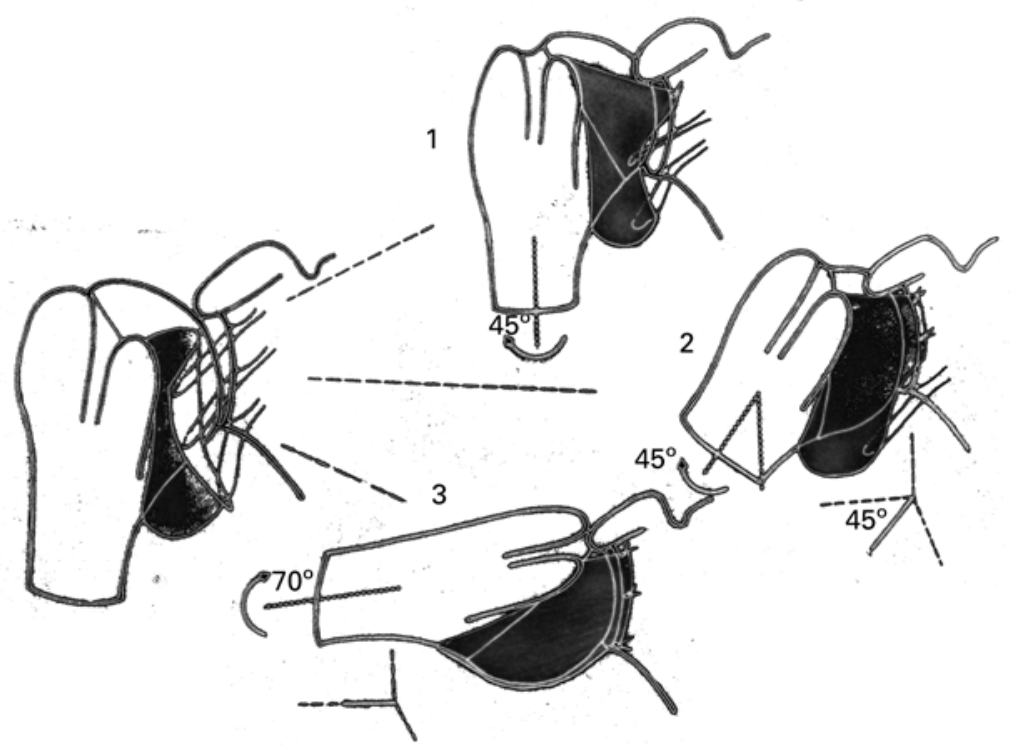

Fig. 3

Diagram of the sutures used in repair of the capsule (see Table I).

forearm pushed down firmly on the shoulder girdle in its lowest position, while lifting the relaxed upper limb in abduction with his other hand. During the test, the elbow was flexed at $90^{\circ}$ and the forearm was horizontal (Fig. 1). Under these circumstances the shoulder girdle should not move. Any movement was recorded with a goniometer. The measurements were made twice by the same operator and repeated by another.

This test was performed in healthy volunteers with normal shoulders and also in volunteers under anaesthesia just before a total hip or knee replacement. Coefficients of correlation between each series of measurements were calculated.

Radiological study. This was undertaken in 20 volunteers, 11 men and nine women with a mean age of 27 years (24 to 30). Radiographs were taken to confirm that the RPA was normal. The beam was horizontal, facing the GHJ and perpendicular to the coronal plane (Fig. 2). Radiographs were taken in two positions of the GHJ with the arm resting across the chest and in full passive abduction. The position of the clavicle was checked on the radiographs. The angle A between the axillary border of the scapula and the vertical line was measured. The projection $(\mathrm{Rv})$ of the angle of rotation of the scapula within the coronal plane was obtained by subtracting the angle A measured in full abduction from that at rest. Thus Rv represented the contribution of the scapula to passive abduction.

Study in patients with instability of the shoulder. Patients with chronic instability of the shoulder after injury were studied for six years. Those with an associated multidirectional hypermobility were excluded leaving patients with a sulcus sign of inferior subluxation of less than $2 \mathrm{~cm}$ of the head of the humerus less than $70^{\circ}$ of external rotation and a significant drawer sign. ${ }^{3}$ There were 56 men and 34 women with a mean age of 24.3 years (18 to 40 ), of whom 60 had recurrent dislocation and 30 transient instability. Measurements of passive abduction were recorded for both shoulders.

The test was also performed under anaesthesia before reconstructive surgery. The condition of the IGHL (torn or 


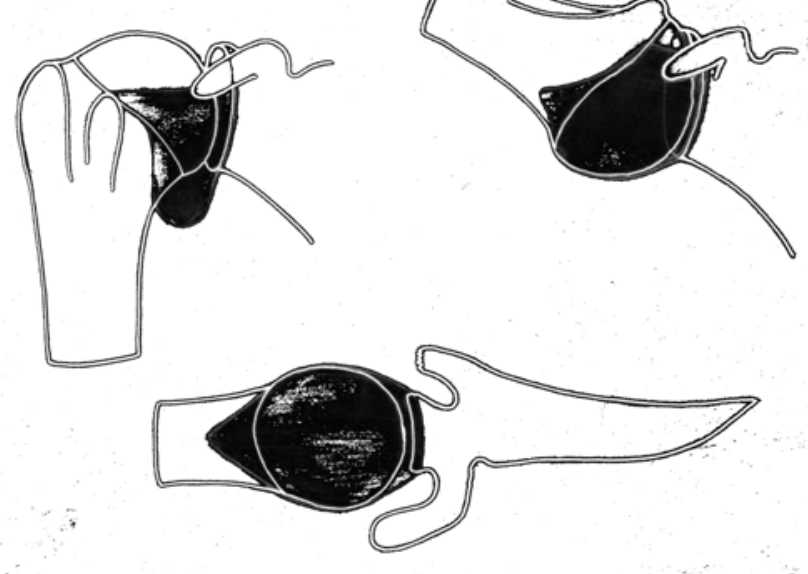

Fig. 4

Diagrams showing a right shoulder in elevation. Top, anteroposterior views: (left) the arm is in a resting position with the IGHL relaxed; (right) the IGHL limits the elevation. Bottom: in full elevation, the IGHL is symmetrically stretched.

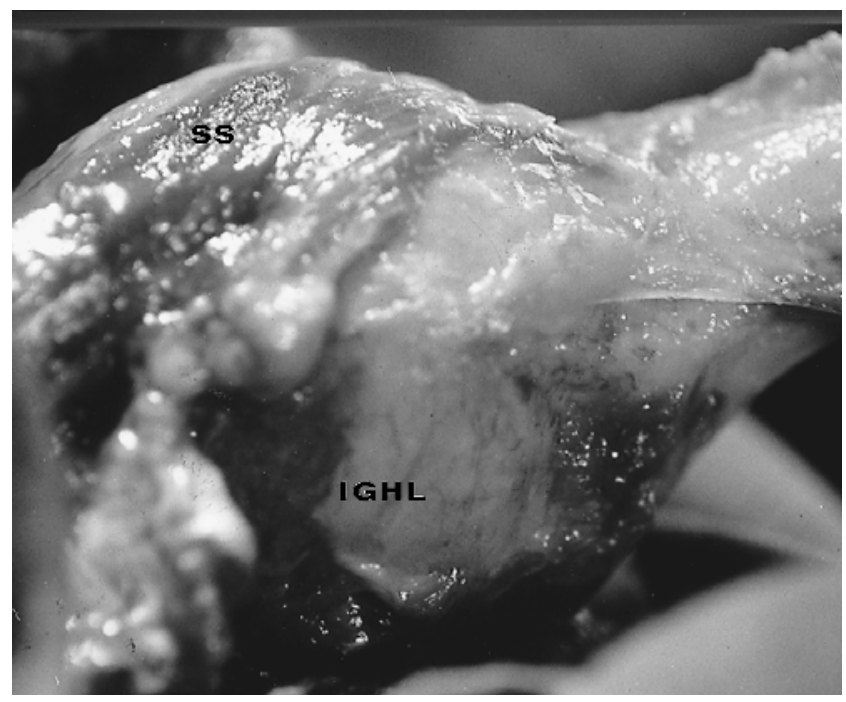

Fig. $6 \mathrm{a}$

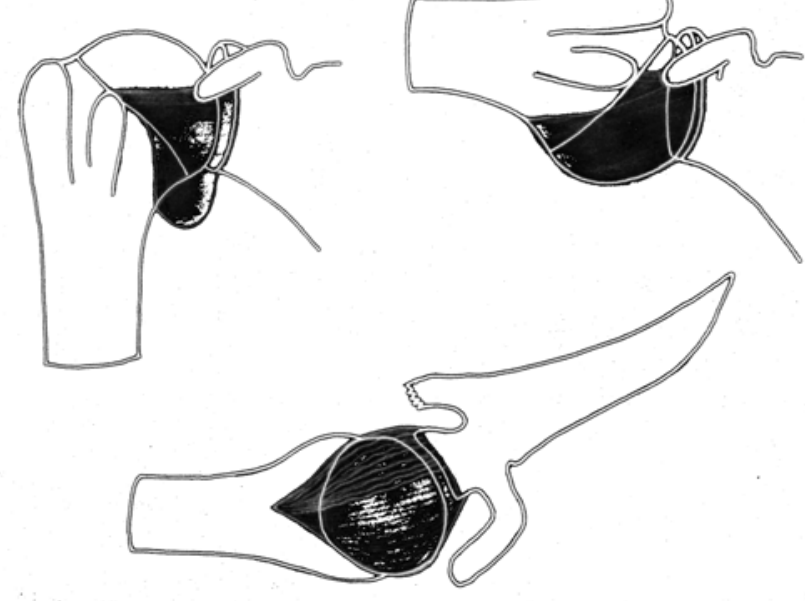

Fig. 5

Diagrams of a right shoulder in abduction. Top, anteroposterior views: (left) the arm is in a resting position with the IGHL relaxed; (right) the IGHL limits the abduction to $90^{\circ}$. Bottom, inferior view: in full abduction only the anterior part of the IGHL is stretched.



Fig. $6 \mathrm{~b}$

Photographs of an anteroinferior view of the left shoulder: the deltoid has been removed. Figure $6 \mathrm{a}-$ The IGHL limits the abduction of the humerus. Figure $6 \mathrm{~b}$ - The detachment of the IGHL from the glenoid rim allows additional abduction (SS, subscapularis muscle; IGHL, inferior glenohumeral ligament).

Table I. Position of the arm during the repair

\begin{tabular}{lccl}
\hline Position of the arm & Flexion $\left({ }^{\circ}\right)$ & Abduction $\left({ }^{\circ}\right)$ & External rotation $\left({ }^{\circ}\right)$ \\
\hline 1 Upper suture & 0 & 0 & 45 \\
2 Middle suture & 45 & 45 & 45 \\
3 Lower suture & 0 & 90 & 70 \\
\hline
\end{tabular}

Table II. Range of movement in the shoulders of cadavers $\left({ }^{\circ}\right)$, IGHL intact

\begin{tabular}{lcc}
\hline & Abduction & Elevation \\
\hline Variance & 2.62 & 6.62 \\
SD & 1.62 & 2.57 \\
Mean value & 83.5 & 107.34 \\
\hline
\end{tabular}

continuous), the type of its insertion into the glenoid and the presence of a Bankart lesion were recorded.

A modified Bankart procedure was performed with sutures being inserted at three positions for the right shoulder, as shown in Figure 3. The position of the arm during insertion of the sutures is given in Table I.

The test was repeated at follow-up.

\section{Results}

Anatomical study in cadavers. The range of elevation was between $105^{\circ}$ and $115^{\circ}$ (Table II). In maximum elevation, the IGHL was symmetrically stretched so that the entire 
Table III. The RPA in volunteers

\begin{tabular}{lccccrr}
\hline & $\begin{array}{l}\text { Right } \\
\text { Op1-1* }\end{array}$ & $\begin{array}{l}\text { Left } \\
\text { Op1-1* }\end{array}$ & $\begin{array}{l}\text { Right } \\
\text { Op1-2 } \dagger\end{array}$ & $\begin{array}{l}\text { Left } \\
\text { Op1-2 } \dagger\end{array}$ & $\begin{array}{c}\text { Right } \\
\text { Op2 } \$\end{array}$ & $\begin{array}{l}\text { Left } \\
\text { Op2 } \$\end{array}$ \\
\hline Variance & 9.90 & 9.67 & 11.03 & 9.09 & 8.31 & 8.04 \\
SD & 3.15 & 3.11 & 3.32 & 3.01 & 2.88 & 2.84 \\
Mean & 89.7 & 89.80 & 89.68 & 89.61 & 89.58 & 89.76 \\
\hline
\end{tabular}

* Op1-1, first test done by the first operator

$\dagger$ Op1-2, second test done by the first operator

$\ddagger$ Op2, test done by the second operator

ligament was responsible for the terminal restriction of elevation; this included the anterior band, the axillary pouch and the posterior band (Fig. 4). The mean abduction was $83.5^{\circ}$ ( 80 to 85 , sD 1.6 ). In maximum abduction, the IGHL was stretched asymmetrically and only its anterior part limited movement (Fig. 5). This portion was attached to the glenoid rim between 3 and 6 o'clock (for a right shoulder). Its section allowed a mean additional abduction of $13^{\circ}$ (10 to 15 ) (Fig. 6). Neither the acromion nor the greater tuberosity limited movement. The range of elevation was not altered by section since the posterior part of the ligament, which was tense in maximum elevation, was left intact. Section of the posterior part of the ligament allowed a mean additional elevation of $12^{\circ}$ (10 to 14).

\section{Study in volunteers}

Clinical. The results are presented in Table III. The mean RPA was $89.7^{\circ}$ on the right and $89.8^{\circ}$ on the left; $95 \%$ of subjects had between $85^{\circ}$ and $90^{\circ}$ of passive abduction and $5 \%$ more than $100^{\circ}$.

In 30 patients with normal shoulders both shoulders were tested under anaesthesia. The mean RPA was $88.6^{\circ}$ (SD 3.5) on the right and $88.9^{\circ}$ (SD 2.1) on the left side (chi-squared test, 0.99).

The coefficients of correlation (Table IV) for the measurements on the same side by the same operator were 0.87 (right) and 0.90 (left). Those for the measurements recorded by two operators on the same side were 0.84 (right) and 0.89 (left).

Radiological. The clavicle remained horizontal on all radiographs. The maximum Rv angle, which describes the rotation of the scapula in the coronal plane, was $5^{\circ}$ (mean value $3^{\circ}$, sD 0.9 ), and the scapula therefore contributed less than $6 \%$ to the RPA (Fig. 7).

Study of patients with instability. In $85 \%$ of cases the

Table IV. Coefficients of correlation of the tests used

\begin{tabular}{ll}
\hline Type of test & Coefficient of correlation \\
\hline Intraoperator, right side & 0.87 \\
Intraoperator, left side & 0.90 \\
Interoperator, right side & 0.84 \\
Interoperator, left side & 0.89 \\
Between left and right & 0.91 \\
sides, operator 1 & \\
Between left and right & 0.88 \\
sides, operator 2 & \\
\hline
\end{tabular}

RPA was more than $105^{\circ}$, as recorded by two physicians (Fig. 8), whereas the maximum on the contralateral side was $90^{\circ}$, except in two, in whom both shoulders were affected. The remaining patients experienced apprehension during the test with reflex muscle contraction; the recording of the RPA was therefore unreliable.

The measurements were repeated under anaesthesia before surgery. The RPA was more than $105^{\circ}$ on the affected side in patients who had experienced apprehension, and less than $90^{\circ}$ on the normal side.

The IGHL was recorded as being in continuity in all patients except two. In one there was a tear on the humeral side, and in the other a complete detachment of the capsule from the glenoid. Labral lesions of varying significance were found in each case. The most significant lesions of the labrum were found in patients with recurrent dislocation. Apart from one patient with a Broca-Hartmann pouch, the IGHL was always attached either directly to the rim of the glenoid or medially along the anterior aspect of the neck of the scapula for up to $6 \mathrm{~mm}$ at most.

At a mean follow-up of 15 months (8 to 36) the RPA was $90^{\circ}$ in 89 of the 90 patients (Fig. 4). The patient with an RPA of more than $105^{\circ}$ was the only early failure in the series, with a tear of the repair which required revision.

\section{Discussion}

There have been many descriptions of the anatomy and function of the IGHL. ${ }^{5-11}$ Some authors have emphasised that elevation and abduction are limited by contact of the greater tuberosity either beneath the acromion ${ }^{12}$ or with the upper margin of the glenoid. ${ }^{13}$ Our study confirms the function of the IGHL in limiting elevation and abduction of the GHJ. The small range of rotation of the scapula during the test demonstrates that passive abduction only occurs at the GHJ and is limited by the IGHL.

Clinically, inferior stability is assessed by the sulcus test ${ }^{2}$ or by the abduction inferior stability (ABIS) test described by Itoi et al, ${ }^{14}$ with the arm at $90^{\circ}$ of abduction. Motzkin, Itoi and Morrey ${ }^{15}$ divided the anteroinferior half of the capsule and recorded significantly increased inferior translation of the humeral head. This suggests that the middle and inferior glenohumeral ligaments contribute to inferior stability with the arm in abduction and also that these ligaments limit abduction.

Of the volunteers $5 \%$ had an RPA of more than $100^{\circ}$ in 




Fig. 7a



Fig. $7 b$

Radiographs showing a shoulder a) at rest, $\mathrm{A}=11^{\circ}$ (see Fig. 2) and b) in full passive abduction, $\mathrm{A}=8^{\circ}$. In this case, the contribution of the scapula to the abduction is $3^{\circ}$.

both shoulders, suggesting increased laxity of the joint. Associated signs of generalised hypermobility were not recorded. There were no shoulders in the anatomical study with increased abduction, probably because of the advanced age of the patients (mean 76 years).

We were able to confirm that the range of elevation of the $\mathrm{GHJ}$ is more important than that of abduction, as has been reported previously. ${ }^{16,17}$ In full elevation, the IGHL is symmetrically tensed at its maximum length whereas in full abduction, the ligament is asymmetrical and thus shorter. It is therefore important to perform the test in the coronal plane.

In patients with chronic instability, the continuity of the IGHL found at surgery and the increase of the RPA seen under anaesthesia show a constant relation between instab-

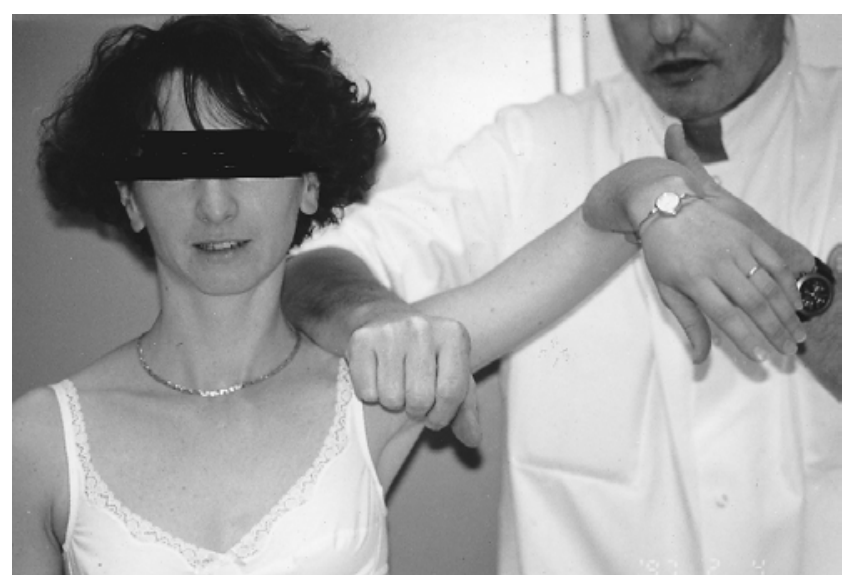

Fig. 8

Photograph showing the demonstration of the positive hyperabduction test. ility and increased length of the IGHL. This confirms the finding of Bigliani et $\mathrm{al}^{18}$ and Urayama et $\mathrm{al}^{4}$ that, at the time of the first dislocation, the IGHL sustains permanent damage, and lengthens further with each dislocation. Speer et al $^{19}$ showed that an experimental Bankart lesion alone did not induce instability. Before operation, the test showed lengthening of the IGHL in $85 \%$ of patients, and thus the measurement of passive abduction may be used as a test of the laxity of the IGHL (hyperabduction test). A positive hyperabduction test $\left(>105^{\circ}\right)$ indicates laxity of the IGHL; a negative test $\left(85^{\circ}\right.$ to $\left.90^{\circ}\right)$ indicates a normal IGHL.

In $15 \%$ of patients, however, passive abduction was limited by apprehension, which contributes to the diagnosis of instability.

The authors thank Gilles Walch, MD and Eiji Itoi, $\mathrm{MD}, \mathrm{PhD}$ for their help with the final preparation of this manuscript.

No benefits in any form have been received or will be received from a commercial party related directly or indirectly to the subject of this article.

\section{References}

1. Gerber C, Ganz R. Clinical assessment of instability of the shoulder: with special reference to anterior and posterior drawer tests. $J$ Bone Joint Surg [Br] 1984;66-B:551-6.

2. Neer CS II, Foster CR. Inferior capsular shift for involuntary inferior and multidirectional instability of the shoulder: a preliminary report. $J$ Bone Joint Surg [Am] 1980;62-A:897-908.

3. Walch G, Agostini J, Levigne C, Nove-Josserand L. Recurrent anterior and multidirectional instability of the shoulder. Rev Chir Orthop Reparatrice Appar Mot 1995;81:682-90.

4. Urayama M, Itoi E, Konno $\mathbf{N}$ et al. Quantitative assessment of capsular elongation in recurrent anterior dislocation of the shoulder using MR arthrography. J Shoulder Elbow Surg 1998;7:328.

5. Ferrari DA. Capsular ligaments on the shoulder: anatomical and functional study of the anterior superior capsule. Am J Sports Med 1990;18:20-4. 
6. Flood V. Discovery of a new ligament of the shoulder joint. The Lancet 1830:672-3.

7. Gagey OJ, Bonfait H, Gillot C, Mazas F. Functional and mechanical anatomy of arm elevation. Rev Chir Orthop Reparatrice Appar Mot 1988;74:209-18.

8. O'Brien SJ, Neves MC, Arnoczky SP, et al. The anatomy and histology of the inferior glenohumeral ligament complex of the shoulder. Am J Sports Med 1990;18:449-56.

9. O'Connel PW, Nuber GW, Mileski RA, Lautenschlager E. The contribution of the glenohumeral ligaments to anterior stability of the shoulder joint. Am J Sports Med 1990;18:579-84.

10. Schlemm F. Uber die Verstärkungsbänder am Schultergelenk. Arch Anat 1853:45-8.

11. Turkel SJ, Panio MW, Marshall JL, Gurgis FG. Stabilizing mechanisms preventing anterior dislocation of the glenohumeral joint. $J$ Bone Joint Surg [Am] 1981;63-A:1208-17.

12. Castaing J, Gouaze A, Soutoul JH, et al. Les éléments anatomiques du blocage de la rotation de l'humérus en abduction maxima de l'articulation scapulo-humérale. C R Assoc Anat 1962:426-35.
13. Henle J. Handbuch der Anatomie des Menschen. Iena: Braunschweig, 1872, T1, 70-6.

14. Itoi E, Motzkin NE, Morrey BF, An K-N. Scapular inclination and inferior stability of the shoulder. $J$ Shoulder Elbow Surg 1992;1:131-9.

15. Motzkin N, Itoi E, Morrey B, An K-N. Contribution of capsuloligamentous structures to passive static inferior glenohumeral stability. Clin Biomech 1985;13:54-61.

16. Gagey O, Bonfait H, Gillot C, Hureau J, Mazas F. Anatomic basis of ligamentous control of elevation of the shoulder (reference position of the shoulder joint). Surg Radiol Anat 1987;9:19-26.

17. Saha AK. Mechanism of shoulder movements and a plea for the recognition of "Zero position" of glenonumeral joint. Clin Orthop 1983;173:3-10.

18. Bigliani LU, Pollock R, Soslowsky L, et al. Tensile properties of the inferior glenohumeral ligament. J Orthop Res 1992;10:187-97.

19. Speer KP, Deng X, Borrerro S, et al. Biomechanical evaluation of a simulated Bankart lesion. J Bone Joint Surg [Am] 1994;76-A:181926. 